\title{
Whither Sex Ratios in a Low Mortality Setting
}

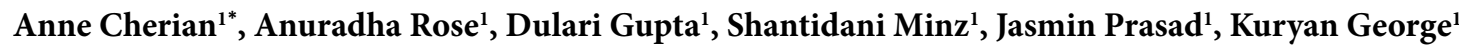

\begin{abstract}
Objectives: Sex ratio at birth should remain constant in the absence of any manipulation. India has shown a worsening sex ratio over the years. Tamil Nadu has shown a remarkable decline in birth rate as well as infant mortality rate. Knowing trends of sex ratio over the years will help us in formulating policies to reduce discrimination.

Materials and Methods: Community Health Department of the Christian Medical College has been operating a detailed demographic surveillance system in Kaniyambadi block in Tamil Nadu since 1982. Data was analyzed to provide estimates of sex ratio at birth, juvenile sex ratio and sex specific infant and perinatal mortality.

Results: There has been a decline in the Infant mortality rate from 67.4 per 1000 live births in 1986 to 16.3 per 1000 live births in 2013. But the sex ratio during 2011-2014 is showing an unfavorable trend. The sex ratio for the first child was 845 females/1000 males. The second pregnancy was not unfavorable but every subsequent pregnancy showed an unfavorable sex ratio.

Conclusion: The study has shown the preference for a male child in the Indian society. The sex of the pre-existing child is a powerful predictor for the next child. The role of modern technology needs to be re-examined in order to address this adverse sex ratio.

Keywords: Child, India, Male, Sex ratio
\end{abstract}

\section{Introduction}

The sex ratio at birth, juvenile sex ratio and population sex ratio are remarkably constant in absence of manipulation. Ratio at birth is defined as the number of female live births per 1000 male live births. The ideal sex ratio in absence of adverse factors is 950 female births/1000 male births. The tradition of son preference, however, has distorted sex ratios in large parts of the world. Son preference is manifested prenatally through sex selective abortions and is evident when sex ratio at birth is examined. Sex discrimination after birth is evident when sex specific infant mortality is examined. The ratio is most distorted in the states of the northern Gangetic Plain, such as Punjab. Haryana remains the direst of all, with only 830 girls per 1000 boys (Daman and Diu 618). It is worrying that certain places that did not discriminate in favour of sons, such as the poorer central and north-eastern states, have begun to do so. The new census showed a worsening sex ratio in all but eight of India's 35 states and territories (though those eight include some of the most extreme examples, for instance, Punjab).

The fears about India's sex ratio are not merely of the harm that today's level will cause when children become adults. People also worry that the ratio will get even worse, deteriorating towards Chinese levels (which are even more extreme: on a comparable basis, China's sex ratio at birth is about 833). The national average is worsening; thanks to states which once were more neutral with regard to sex, such as Tamil Nadu and Orissa.

There has been increasing international news coverage of the excess of young boys in India resulting from the abortion of female fetuses (1). The strong preference for sons is especially evident in some Indian states, but the practice of sex-selective abortion to ensure a male child has been documented in many parts of India and among Indians living abroad. Sex-selective abortion has been primarily used by wealthier Indians who can afford the ultrasound fee of 500 rupees (\$US 12) to determine the sex of a fetus. The increasing availability of ultrasound has been linked to the sharp rise in the ratio of male births to female births in some parts of India in recent decades. Female infanticide is still practiced in some parts of our country.

Tamil Nadu has shown remarkable decline in birth rate and in infant mortality with consequent reduction in average family size. It is normally expected that increasing survival and smaller families will lead to reduction in the sex specific differential mortality and in the sex based discrimination. Paradoxically, it has been seen in some societies that increasing survival and lower mortality exaggerate the pre-existing male-female differential mortality. We examined the data collected by The Health information system of the Community Health and Development Program of CMC Vellore to see the sex ratio at birth and the sex specific infant and perinatal mortality rate.

\section{Materials and Methods \\ The Community Health department of the Christian Medical College through its Community Health and De- velopment (CHAD) Program has been delivering health care services to the entire Kaniyambadi block since 1982.}


A detailed demographic surveillance system (DSS) has been operational in this block since 1986. The Kaniyambadi block, the CHAD Program and the DSS is described in detail elsewhere. Data regarding the sex of live births and sex wise infant and perinatal mortality was extracted from the DSS and analyzed to provide estimates of sex ratio at birth, juvenile sex ratio and sex specific infant and perinatal mortality.

\section{Results}

The sex ratio at birth was examined in 5 year periods. The point estimates of the sex ratio at birth were unfavourable in the time period 1986-1990, 1991-1995 and 2011-2014. The sex ratio was favourable for girls in the time period 1996-2000, 2001-2005 and 2006-2110 (Table 1). The unfavourable sex ratio at birth in the earlier period (1986-
1995) could have been attributed to the practice of wrongly identifying very early neonatal deaths as still births. It is a matter of concern that the sex ratio in 2011-2114 has reversed from a favourable to an unfavourable sex ratio. The period 1986-2013 has shown a decline in infant mortality rate (IMR) from 67.4/1000 live births in 1986 to 16 . $3 / 1000$ live births in 2013 (Table 2). The crude birth rate (CBR) has declined from 22.1/1000 population in 1986 to $13.1 / 1000$ population in 2013 . However, the juvenile sex ratio has remained constant at around 940/1000 males (Table 3).

The sex ratio at birth was examined by birth order. The sex ratio at birth for the first child was 845 females/ 1000 males. This may indicate a son preference for the first child. The second pregnancy was not unfavourable. All subsequent pregnancies showed an adverse sex ratio (Table 4). The sex

Table 1. Sex Ratio at Birth- Kaniyambadi Bock 1986-2013

\begin{tabular}{lllll}
\hline Year & No. of Male Births & No. of Female Births & Sex Ratio (Female Live Births/1000 Male Live Births ) \\
\hline $1986-1990$ & 4960 & 4559 & 919 & 936 \\
$1991-1995$ & 4760 & 4457 & 950 & Less than ideal \\
$1996-2000$ & 4408 & 4192 & 984 & Ideal \\
$2001-2005$ & 4124 & 4057 & 951 & Ideal \\
$2006-2010$ & 3730 & 3547 & 910 & Ideal \\
$2011-2014$ & 2646 & 2408 & Ideal \\
\hline
\end{tabular}

*Ideal sex ratio Greater than 950 females per 1000 males.

Table 2. Sex Specific Infant and Perinatal Mortality-Kaniyambadi Block 1986-2013

\begin{tabular}{|c|c|c|c|c|c|c|c|c|}
\hline \multirow{2}{*}{ Year } & \multicolumn{4}{|c|}{ Male } & \multicolumn{4}{|c|}{ Female } \\
\hline & IMR & PMR & Neonatal & Post-neonatal & IMR & PMR & Neonatal & Post-neonatal \\
\hline 1986 & 62.2 & 55.4 & 33.6 & 28.5 & 79.4 & 64.4 & 47.4 & 32 \\
\hline 1987 & 56.3 & 45.3 & 34.2 & 22.1 & 65 & 38.3 & 33.1 & 31.9 \\
\hline 1988 & 61.1 & 52 & 35.5 & 25.6 & 63.2 & 54.2 & 36.4 & 26.8 \\
\hline 1989 & 53.4 & 54.7 & 30.2 & 23.2 & 47.1 & 45.8 & 25.1 & 22 \\
\hline 1990 & 48.8 & 46.9 & 31.9 & 16.9 & 53 & 34.2 & 27.5 & 25.5 \\
\hline 1991 & 50.3 & 40.9 & 26.6 & 23.7 & 53 & 35.6 & 25.4 & 27.6 \\
\hline 1992 & 46.3 & 41.4 & 31.2 & 15.1 & 44.1 & 30.2 & 18.7 & 25.3 \\
\hline 1993 & 43.7 & 55.7 & 26.5 & 17.3 & 39.3 & 38.4 & 25.1 & 14.2 \\
\hline 1994 & 39.4 & 37.8 & 25.6 & 13.8 & 40.2 & 40.5 & 25.3 & 14.9 \\
\hline 1995 & 29.8 & 38.8 & 17.7 & 12.2 & 43.1 & 37.8 & 28 & 15.2 \\
\hline 1996 & 43.2 & 50.4 & 31 & 12.2 & 54.2 & 52.6 & 30.6 & 23.6 \\
\hline 1997 & 43.3 & 44.4 & 34.4 & 8.9 & 33.4 & 33.9 & 21 & 12.4 \\
\hline 1998 & 33.5 & 39.9 & 24 & 9.6 & 39.8 & 33 & 23.6 & 16.2 \\
\hline 1999 & 24.3 & 37.3 & 17.4 & 6.9 & 38 & 44.1 & 27.3 & 10.7 \\
\hline 2000 & 29.8 & 38.8 & 22.1 & 7.7 & 39.4 & 39.6 & 25.9 & 13.5 \\
\hline 2001 & 40.5 & 35.3 & 23.1 & 17.4 & 34.3 & 29.4 & 20.6 & 13.7 \\
\hline 2002 & 29.2 & 38.3 & 20.7 & 8.5 & 33.8 & 32 & 19.5 & 14.3 \\
\hline 2003 & 36.9 & 24.3 & 16 & 20.9 & 41 & 39 & 26.4 & 14.5 \\
\hline 2004 & 38.3 & 32.7 & 26.8 & 11.5 & 34.8 & 38.1 & 20.9 & 13.9 \\
\hline 2005 & 27 & 30.3 & 14.2 & 12.9 & 31.5 & 44.4 & 20 & 11.4 \\
\hline 2006 & 31.5 & 37.8 & 20 & 11.4 & 24.6 & 36.1 & 15.4 & 9.2 \\
\hline 2007 & 21.8 & 37.3 & 16.4 & 5.5 & 27.6 & 29.8 & 22.1 & 5.5 \\
\hline 2008 & 33.2 & 41.9 & 22.1 & 11.1 & 17.4 & 28.3 & 13 & 4.3 \\
\hline 2009 & 26.3 & 39.3 & 21.3 & 5 & 12.1 & 21.2 & 9.4 & 2.7 \\
\hline 2010 & 33.4 & 35.5 & 27 & 6.4 & 21.7 & 17.4 & 9.5 & 12.2 \\
\hline 2011 & 24.2 & 37.4 & 20.4 & 3.8 & 12.3 & 22.8 & 6.8 & 5.5 \\
\hline 2012 & 21.3 & 35.5 & 18.8 & 2.5 & 29.7 & 30.6 & 21.2 & 8.5 \\
\hline 2013 & 20.8 & 25.6 & 14.3 & 6.5 & 11.4 & 19.6 & 9.9 & 1.4 \\
\hline
\end{tabular}

Abbreviations: IMR, infant mortality rate; PMR, perinatal mortality rate. 
ratio at birth of all subsequent pregnancies was examined based on the sex of the first child. If the first child was a male, the sex ratio was favourable for girls in all the subsequent pregnancies. If the first child was a girl, the sex ratio was favourable for girls only for the second pregnancy but was unfavourable later (Table 5). The sex ratio at birth was examined for subsequent pregnancies based on the sex of the first two children. If both were males the sex ratio was favourable for girls. If the first child was male and second female, then the sex ratio was favourable for girls in the third pregnancy but not thereafter. If the first was a girl and second a boy, the sex ratio was unfavourable for girls. This trend was further accentuated if both children were girls (Table 6). The sex-specific infant and perinatal mortality was examined for the period 1986-2013. There was no consistent pattern of sex specific differences in infant and perinatal mortality (Figure 1).

\section{Discussion}

The juvenile sex ratio has been the focus of attention primarily as an indicator of female infanticide. In this study the infant mortality rate, perinatal mortality rate and birth rate have shown an impressive decline. This has unfortunately also been accompanied by a worsening of sex ratio. This could be possibly being due to the widespread use of ultrasound scans during pregnancy as a sex determination

Table 3. Juvenile Sex Ratio/1000 Males (0-6)

\begin{tabular}{ll}
\hline Year & Juvenile Sex Ratio \\
\hline 2005 & 934 \\
2010 & 948 \\
2013 & 939 \\
\hline
\end{tabular}

Table 4. Sex Ratio by Number of Living Children

\begin{tabular}{lll}
\hline Birth Order & No. of Pregnancies & Sex Ratio at Birth \\
\hline 1 & 1879 & 845 \\
2 & 1828 & 995 \\
3 & 559 & 803 \\
4 & 80 & 568 \\
5 & 13 & 444 \\
6 & 6 & 500 \\
7 & 1 & 0 \\
\hline
\end{tabular}

Table 5. Sex Ratio at Birth Based on Sex of First Child

\begin{tabular}{lcccc}
\hline \multirow{2}{*}{ Sex of first child } & $\mathbf{2}$ & $\mathbf{3}$ & $\mathbf{4}$ & $\mathbf{5}$ \\
\cline { 2 - 5 } & 968 & 1009 & 1090 & 333 \\
Male & 1028 & 694 & 425 & 500 \\
\hline
\end{tabular}

Table 6. Sex Ratio at Birth Based on Sex of First Two Children

\begin{tabular}{lccc}
\hline & 3 & 4 & 5 \\
\hline Male, male & 928 & 2250 & 1000 \\
Male, female & 1098 & 428 & \\
Female, male & 758 & 714 & 500 \\
Female, female & 659 & 363 & 500
\end{tabular}

tool and subsequent sex selective abortions and feticide. However, a 'lower than normal' female sex ratio at birth is not always the result of sex-selective abortion of the female foetus. There are many factors that can cause a decline in sex ratio at birth, of which sex-selective abortion of the female foetus is only one.

Several other hypotheses have been put forward and examined to explain the reasons for a decline in the male sex ratio at birth. These include psychological stress in the mother, especially in the first trimester of pregnancy (13 ), exposure to occupational and reproductive hazards by men (4), economic collapse (5) and conflicts or war (6). In India, the female-to-male ratio at birth had shown a decrease much before the advent of modern technologies of sex determination. Sex ratio at birth (SRB) decreased from 934.6 females per 1000 males during 1901-1910, to 909 females per 1000 males in 1940-1946 in all the major provinces of British India except Bombay and Assam (7). This was because of deterioration in the completeness of vital registration data in British India.

Increase in male births is an important factor contributing to the decrease in female sex ratio at birth. India's demographic transition has given rise to a number of changes all of which have the effect of increasing the number of male births.

Biologically more male foetal losses are likely through miscarriage or stillbirth. Advances in healthcare which bring about a decline in these rates will contribute to a slight increase in the proportion of male births. This is corroborated by data from NFHS-1 and NFHS-2. These show that the sex ratio at birth has a higher proportion of males for women who have had trained attendance at delivery (8).

Evidence from many studies based on large data sets shows that, biologically, there are more males than females among first births. The proportion of male births declines with each subsequent birth $(9,10)$. This means that when couples limit their family size, and therefore fewer children of higher order are born, the proportion of male births will increase.

In societies with a high preference for sons, the adoption of a small family norm often leads to couples stopping childbearing as soon as they beget one or two male children. Because there are relatively more male first and second births, the proportion of male births in the popula-

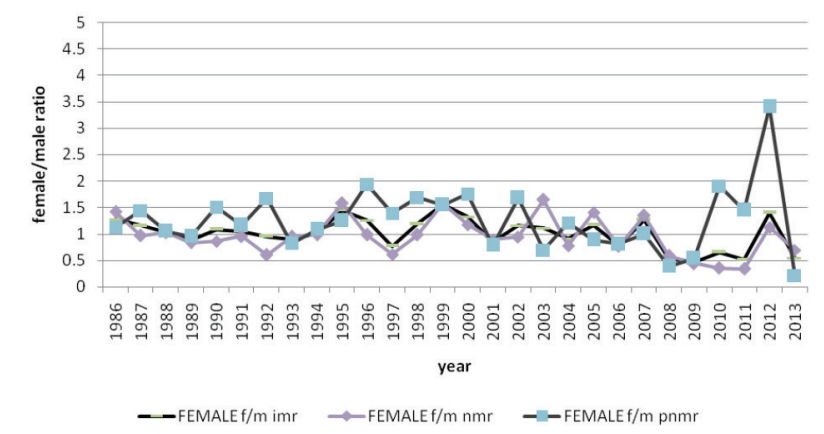

Figure 1. Male and Female Differential in Infant, Neonatal and Postnatal Mortality. 
tion may increase to some extent as a result of this.

Biologically, shorter birth intervals are associated with a higher proportion of male births (11). When couples decide to start childbearing soon after marriage and have children in quick succession and then adopt a permanent method of contraception, this is likely to have an influence on the proportion of male births in the population.

Many studies report that males are more frequently conceived at the beginning and at the end of the menstrual cycle $(12,13)$. In other words, if couples practise 'natural' family planning and avoid intercourse during the most fertile period of the menstrual cycle -the middle of the menstrual cycle-the probability of a male child being conceived increases $(14,15)$.

\section{Conclusion}

The study has indicated that the sex of the pre-existing child is a powerful predictor of the sex of subsequent children. A pre-existing girl child may encourage sex selection in subsequent pregnancies. This has occurred in milieu where the small family is the norm and there are no obvious differences in infant and perinatal mortality based on sex. This study has shown that son preference is still an influence in our community. The role of modern technology in ensuring an unfavourable sex ratio for girls needs to be examined and introspected on before evolving strategies to address this adverse event.

\section{Ethical Issues}

Not applicable.

\section{Conflict of Interests}

The authors declare no conflict of interests.

\section{Financial Support}

The researchers received no financial support or grant from any funding agency in the public and commercial sectors.

\section{Acknowledgments}

We would like to acknowledge all those working in the Community Health Department of CMC, Vellore for their tireless efforts at maintaining such a good database.

\section{References}

1. Obel C, Henriksen TB, Secher NJ, Eskenazi B, Hedegaard M. Psychological distress during early gestation and offspring sex ratio. Hum Reprod. 2007;22(11):3009-3012. doi:10.1093/humrep/ $\operatorname{dem} 274$.

2. Trivers RL, Willard DE. Natural selection of parental ability to vary the sex ratio of offspring. Science. 1973;179(4068):90-2.

3. Catalano R, Bruckner T, Marks AR, Eskenazi B. Exogenous shocks to the human sex ratio: the case of September 11, 2001 in New York City. Human Reprod. 2006;21(12):3127-3131. doi: 10.1093/humrep/del283.

4. Alexopoulos EC, Alamanos Y. Secondary sex ratio in Greece: evidence of an influence by father's occupational exposure. Hum Reprod 2007;22(11):2999-3001. doi:10.1093/humrep/ dem309.

5. Catalano RA. Sex ratios in the two Germanies: a test of the economic stress hypothesis. Hum Reprod. 2003;18(9):1972-1975. doi:10.1093/humrep/deg370.

6. Ansari-Lari M, Saadat M. Changing sex ratio in Iran 1976-2000. J Epidemiol Community Health. 2002;56(8):622-623.

7. Visaria P. The sex ratio of the population of India. Monograph No 10, Census of India, 1961. Delhi: Manager of Publications; 1971.

8. Mari Bhat PN, Zavier AJF. Factors influencing the use of prenatal diagnostic techniques and the sex ratio at birth in India. Econ Polit Wkly. 2007;42(24):22922303.

9. Erickson JD. The secondary sex ratio in the United States 1969-71: association with race, parental ages, birth order, paternal education and legitimacy. Ann Hum Genet. 1976;40(2):205-212.

10. James WH. The human sex ratio. Part 1: A review of the literature. Hum Biol. 1987;59(5):721-752.

11. James WH. Interpregnancy intervals, high maternal age and seasonal effects on the human sex ratio. Hum Reprod. 1996;11(1):7-8.

12. James WH. Sex ratio, coital rate, hormones and time of fertilization within the cycle. Ann Hum Biol. 1997;24(5):403-409.

13. Sieff DF. Explaining biased sex ratios in human populations: A critique of recent studies. Curr Anthropol. 1990;31(1):25-48.

14. Gray RH. Natural family planning and sex selection: fact or fiction? Am J Obstet Gynecol. 1991;165(6 Pt 2):1982-1984.

15. James WH. The status of the hypothesis that the human sex ratio at birth is associated with the cycle day of conception. Hum Reprod. 1999;14:2177-2180. doi:10.1093/humrep/14.8.2177A.

Copyright $\odot 2016$ The Author(s); This is an open-access article distributed under the terms of the Creative Commons Attribution License (http://creativecommons.org/licenses/by/4.0), which permits unrestricted use, distribution, and reproduction in any medium, provided the original work is properly cited. 